Call for Papers

\title{
Music and the Spanish Civil War
}

\section{$8-10$ October 2020}

Humboldt University, Berlin

Convened by Diego Alonso (Postdoctoral Fellow, Humboldt University, Berlin) in collaboration with the International Hanns Eisler Society, Berlin. The conference is supported by the Deutsche Forschungsgemeinschaft.

\section{Keynote speakers:}

Michael Christoforidis \& Elizabeth Kertesz (U. of Melbourne, Australia) Gemma Pérez Zalduondo (U. of Granada, Spain)

Until recently, the Spanish Civil War (1936-1939) was frequently considered a time of paralysis, a parenthesis between the rich musical life of early $20^{\text {th }}$-century Spain and the new cultural and musical landscape of post-war Spain under Franco's dictatorship. Accordingly, we still lack a thorough account of the role played by music and music criticism in this crucial period of Spain's recent history. Similarly, the international impact of the Civil War on music has been explored only sporadically. These studies have focused primarily on a few musicians and a small selection of works, rather than more fully examining the range of activities, productions and debates involving music in and beyond Spain.

This two-day conference aims to create a framework for a broader understanding of the ways in which Spanish and non-Spanish musicians (including composers, performers, conductors, musicologists, critics, and others) relate to this key historical and ideological conflict of the $20^{\text {th }}$ century. These relationships are not limited to the wartime period but also include the subsequent decades, in which a large number of musicians from Spain and abroad reflected on the confrontation and its consequences in their work.

Our focus is on the musical/sonic experiences and soundscapes in wartime Spain as well as the direct responses to the Civil War in the fields of music, musicology and music criticism from 1936 to the present. Principal themes include the links between music/sound and political warfare (both within institutional and non-institutional contexts), the use of music and music criticism for delivering a specific political message to a targeted audience, and the processes through which collective identities were constructed through music in wartime Spain. We particularly welcome papers that examine transnational relationships in the field of musical propaganda as well as those discussing activities, figures, and musics occupying spaces deemed liminal -and thus generally neglected-in prevailing accounts of the role of music in the Spanish Civil War. 
Suggested themes include, but are not limited to:

Music/sound and political warfare in Spain

Fascist/antifascist musical and radio propaganda

Musical practices at the front/home front

Sonic experiences and soundscapes in wartime Spain

Music and the International Brigades

New forms of popular music and musical theatre during the war

Activities of foreign or exiled musicians in or about wartime Spain

Works written and performed outside of Spain in solidarity with participants in the War

Musicology, music criticism, or music journalism and the Spanish Civil War

The Spanish Civil War in music practices and discourses after 1939

We invite proposals from scholars exploring these and related questions in relation to any musical practice. The official language of the conference is English (preferably). German and Spanish are also possible.

Accepted formats for presentations include but are not limited to:

- Individual papers (20 minutes followed by 10 minutes of discussion time)

- Themed sessions of 3 papers (20 minutes each, with 10 minutes per paper for discussion + 15 minutes afterwards)

Each proposal should include:

* The author's name and affiliation

* Email address

* An abstract of no more than 350 words (for sessions, an additional max. 250-word abstract per paper/person)

* A short biography (no more than 150 words)

* Any technical requirements

Please submit proposals to diego.alonso.tomas@hu-berlin.de by the deadline of 1 March 2020. The programme will be announced by early April 2020.

\section{Conference Supporters:}

Deutsche Forschungsgemeinschaft Internationale Hanns Eisler Gesellschaft

Humboldt-Universität zu Berlin

\section{Programme Committee:}


Teresa Cascudo (Universidad de La Rioja)

Johannes C. Gall (Internationale Hanns Eisler Gesellschaft, Berlin)

Germán Gan Quesada (Universitat Autònoma de Barcelona)

Carol A. Hess (University of California, Davis)

Christian Koller (Universität Zürich)

Beatriz Martínez del Fresno (Universidad de Oviedo)

Eva Moreda (University of Glasgow)

Peter Schweinhardt (Internationale Hanns Eisler Gesellschaft, Berlin)

Elena Torres (Universidad Complutense de Madrid)

Cristina Urchueguía (Universität Bern) 